\title{
BMJ Open Can training in advanced clinical skills in obstetrics, neonatal care and leadership, of non-physician clinicians in Malawi impact on clinical services improvements (the ETATMBA project): a process evaluation
}

\author{
David R Ellard, ${ }^{1}$ Wanangwa Chimwaza ${ }^{2}$ David Davies, ${ }^{3}$ Joseph Paul O'Hare, ${ }^{4}$ \\ Francis Kamwendo, ${ }^{5}$ Siobhan Quenby, ${ }^{6}$ Frances Griffiths, ${ }^{7}$ On behalf of \\ The ETATMBA Study Group
}

To cite: Ellard DR,

Chimwaza W, Davies D, et al. Can training in advanced clinical skills in obstetrics, neonatal care and leadership, of non-physician clinicians in Malawi impact on clinical services improvements (the ETATMBA project): a process evaluation. BMJ Open 2014:4:e005751.

doi:10.1136/bmjopen-2014005751

- Prepublication history and additional material is available. To view please visit the journal (http://dx.doi.org/ 10.1136/bmjopen-2014005751).

Received 22 May 2014 Revised 15 July 2014 Accepted 24 July 2014

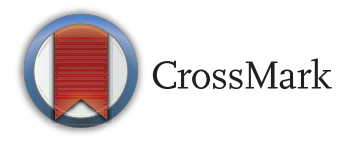

For numbered affiliations see end of article.

Correspondence to Dr David R Ellard; d.r.ellard@warwick.ac.uk

\section{ABSTRACT}

Objectives: The 'enhancing human resources and the use of appropriate technologies for maternal and perinatal survival in sub-Saharan Africa' (ETATMBA) project is training emergency obstetric and new-born care (EmONC) non-physician clinicians (NPCs) as advanced clinical leaders. Our objectives were to evaluate the implementation and changes to practice.

Design: A mixed methods process evaluation with the predominate methodology being qualitative.

Setting: Rural and urban hospitals in 8 of the 14 districts of northern and central Malawi.

Participants: 54 EmONC NPCs with 3 years' plus experience.

Intervention: Training designed and delivered by clinicians from the UK and Malawi; it is a 2-year plus package of training (classroom, mentorship and assignments).

Results: We conducted 79 trainee interviews over three time points during the training, as well as a convenience sample of 10 colleagues, 7 district officers and 2 UK obstetricians. Trainees worked in a context of substantial variation in the rates of maternal and neonatal deaths between districts. Training reached trainees working across the target regions. For 46 trainees (8 dropped out of the course), dose delivered in terms of attendance was high and all 46 spent time working alongside an obstetrician. In early interviews trainees recalled course content unprompted indicating training had been received. Colleagues and district officers reported cascading of knowledge and initial changes in practice indicating early implementation. By asking trainees to describe actual cases we found they had implemented new knowledge and skills. These included life-saving interventions for postpartum haemorrhage and eclampsia. Trainees identified the leadership training as enabling them to confidently change their own practice and initiate change in their health facility.

\section{Strengths and limitations of this study}

- This is the first study to take an in-depth look at training of non-physician clinicians in subSaharan Africa and the first to look at how this training is accepted by the trainees and how they then go on to implement this training into their practice.

- The results of the evaluation are very positive with trainees showing a high regard for the training and demonstrating that the training has had a positive impact on their clinical practice.

- The results suggest that the training has enabled the lives of mothers and babies to be saved.

- Limiting factors are that while it appears that the trainees have made a difference, they are a small cohort and the impact on national maternal and neonatal mortality rates may be difficult to see. It is also possible in studies like this that trainees report what they consider socially acceptable to the evaluation team. However, reports of 'real' events suggest that this is not the case.

- This cadre is an important component in helping relieve the chronic shortages of trained medical professionals in sub-Saharan Africa and helping countries move towards realisation of millennium development goals. Further evaluations of the up-skilling of this cadre are needed.

Conclusions: This process evaluation suggests that trainees have made positive changes in their practice. Clear impacts on maternal and perinatal mortality are yet to be elucidated.

\section{INTRODUCTION}

Enhancing human resources and the use of appropriate technologies for maternal and 
perinatal survival in sub-Saharan Africa (ETATMBA) is a European commission (FP7) funded project. In northern and central Malawi it is providing advanced clinical and leadership training (between November 2011 and June 2014) to non-physician clinicians (NPCs) who provide emergency obstetric and new-born care (EmONC).

A widespread crisis in the health workforce is affecting the realisation of health-related millennium development goals. ${ }^{12}$ There is also an imbalance in the range of health worker skills with many countries having too few specialist doctors such as surgeons, obstetricians and anaesthetists, relative to the health needs of their population.

An important indicator of the global personnel shortage in the health sector is the proportion of women assisted by skilled birth attendants. ${ }^{3}$ In most industrialised countries, skilled birth attendance is provided at almost all births while fewer than $50 \%$ of births in the majority of countries in South Asia and sub-Saharan Africa receive such support. ${ }^{4}$ Estimates show that skilled birth attendance rates are only improving at less than $0.5 \%$ per year: by 2015 it is likely that it will still be fewer than $50 \%$ of births where there is the support of a skilled birth attendant. ${ }^{5}$

To address the global health workforce crisis many countries are now considering task-shifting strategies. Task shifting from physicians to non-physicians appears to be both safe and effective in countries that have organised and supported the extension of their maternal care in this way. ${ }^{6-12}$ In Malawi, NPCs have been established health providers since 1976 performing surgical procedures, giving anaesthetics and providing medical care. $^{13} 14$ There are no clear career pathways for NPCs who are often undervalued. ${ }^{15}{ }^{16}$ Enhancing the skills of this cadre is a vital approach to improving healthcare for mothers and babies in sub-Saharan Africa where there are few medical doctors. The WHO has made recommendations to optimise the NPCs role in maternal and new-born health. ${ }^{17}$

The evaluation of ETATMBA involves a cluster randomised controlled trial with process evaluation. ${ }^{18}$ We report the process evaluation of the training. We report how the programme of training has been received and look for evidence that individual practice may have changed as a result. ${ }^{19}$

\section{The setting and intervention}

Fifty NPCs working in EmONC were drawn from eight districts in central and northern Malawi to undertake the training (see online supplementary appendix).

Briefly, the training package was a 30-month programme of knowledge and skills training including mentoring of practice. In addition, two obstetricians at specialist registrar level with 5 years of clinical experience worked alongside the NPC, each for 2 weeks in each district, providing peer support and sharing skills and knowledge. Figure 1 contains a summary of the content of the training modules and further details are on the ETATMBA website ${ }^{20}$ (see online supplementary appendix).

\section{METHODS}

We used a mixed methods approach for this process evaluation with the predominate data being qualitative (see table 1).

Semistructured interviews were carried out at three time points. The first set of interviews was undertaken 4-5 months after the delivery of module 1 with a convenience sample of trainees. A researcher (WC) visited each intervention district for 1-2 days and interviewed ETATMBA trainees available during the visit. During the interviews, we asked the trainees about their perceptions of the training and support. With no prompting about training content we then asked them what new knowledge they gained. A researcher (WC) undertook the second set of interviews during 1-2-day visits to each intervention district 4-5 months after delivery of the second module on clinical leadership. We interviewed available trainees, asking them about training content and its implementation in their clinical work. We did this without prompting them. We then prompted them to talk about challenges and successes in using and sharing these skills in their facilities. We interviewed, during data collection visits, available district medical and nursing officers, exploring how they perceived the training and how it had fitted into their hospital. The researcher also asked the trainees to identify colleagues (cascadees) such as nurses, nurse midwives or NPCs to whom they had delivered some training. The researcher then sought interviews with available cascadees about the delivery and content of training they had received. Three researchers (WC, DRE and FG) carried out a third set of interviews with trainees, in an amendment to the protocol, while they were attending the week-long residential delivery of modules 5 and 6 . We asked the trainees to provide specific examples of how they had used the training in their clinical work, describing actual cases. In the first part of the interview, we used no prompts about course content. In the latter part of the interview, trainees were asked to provide the examples from their clinical work of the application of each of the following key aspects of the training: delivery skills breech, vacuum extraction, caesarean section, neonatal resuscitation, management of postpartum haemorrhage $(\mathrm{PPH})$, the use of partograms. At this time, we also interviewed the two obstetricians who had worked alongside the NPCs.

Data were drawn from Malawi Ministry of Health $(\mathrm{MOH})$ documents for describing the context of the trial. ${ }^{21}$ Data from the MOH data on the pool of NPCs from which recruits were selected in the intervention districts are used to describe the reach of the intervention. Dose delivered is assessed using attendance and assignment submission logs. 


\begin{tabular}{|c|c|c|}
\hline Timeline & \multicolumn{2}{|c|}{ Modules \& Research Activity } \\
\hline Nov-Dec 2011 & $\begin{array}{l}\text { Module 1: Clinical Officers as Advanced } \\
\text { Leaders } \\
\text { This concentrated on the five major causes of } \\
\text { maternal mortality in Malawi, } \\
\text { hypertension/eclampsia, postpartum } \\
\text { haemorrhage, post delivery sepsis, sepsis after } \\
\text { unsafe abortion, obstructed labour. }\end{array}$ & $\begin{array}{l}\text { Simulation and skill drills on emergency } \\
\text { obstetrics included, external cephalic version, } \\
\text { vaginal breech, postpartum haemorrhage, B } \\
\text { Lynch suture, shoulder dystocia, eclamptic fit, } \\
\text { vaccum extraction, obstructed labour } \\
\text { (partograph) }\end{array}$ \\
\hline April - May 2012 & \multicolumn{2}{|c|}{$1^{\text {st }}$ interviews: $\mathrm{N}=19$ Trainees } \\
\hline May - June 2012 & $\begin{array}{l}\text { Module 2: Clinical service improvement and } \\
\text { leadership in emergency obstetric and neonatal } \\
\text { care } \\
\text { Introduction to leadership } \\
\text { Behaviours and leadership skills } \\
\text { Leading and managing change } \\
\text { Introduction to service improvement and problem } \\
\text { identification } \\
\text { Service improvement and values stream mapping } \\
\text { Introduction to values based practice }\end{array}$ & $\begin{array}{l}\text { Key concepts in values based practice } \\
\text { Introduction to Clinical Leadership Compentency } \\
\text { Framework (CLCF) } \\
\text { (trainees expected to use new leadership skills on } \\
\text { return to district) } \\
\text { Quality improvement in obstetrics } \\
\text { Audit workshop (assignments given and audits } \\
\text { conducted on return to districts (completion Nov } \\
2012 \text { ) } \\
\text { Neonatal care videos (eight training videos } \\
\text { covering a variety of topics) }\end{array}$ \\
\hline Oct - Nov 2012 & \multicolumn{2}{|c|}{$2^{\text {nd }}$ Interviews: $\mathrm{N}=12$ Trainees, $\mathrm{N}=10$ Cascadees, $\mathrm{N}=7 \mathrm{DMO} / \mathrm{DNO}$} \\
\hline Nov - Dec 2012 & $\begin{array}{l}\text { Module 3: Born too soon } \\
\text { Neonatal survival in Malawi } \\
\text { Essential and extra newborn care } \\
\text { Gestational age } \\
\text { Preterm neonatal resuscitation }\end{array}$ & $\begin{array}{l}\text { Special care of preterm babies } \\
\text { Kangaroo mother care } \\
\text { Evidence-based medicine } \\
\text { Second and third trimester scanning technique } \\
\text { Setting up the machine (ultrasound scanner) }\end{array}$ \\
\hline Dec 2012 - Feb 2013 & \multicolumn{2}{|c|}{ Module 4 "Professional project" involving a literature review, audit and re-audit. } \\
\hline \multirow{3}{*}{ May - June 2013} & $\begin{array}{l}\text { Module 5: Understanding research evidence } \\
\text { and critical appraisal } \\
\text { Training NPCs } \\
\text { Introduction to evidence-based medicine } \\
\text { Evidence-based medicine overview } \\
\text { Bias } \\
\text { Interaction } \\
\text { How to read an academic paper } \\
\text { How to critically appraise an article } \\
\text { Critical Appraisal Skills Programme }\end{array}$ & $\begin{array}{l}\text { Helsinki Ethical Principles for Medical Research } \\
\text { National Health Services Research Committee of } \\
\text { Malawi: Guidelines } \\
\text { National Health Services Research Committee of } \\
\text { Malawi: Application form } \\
\text { Revised guidelines and operational procedures } \\
\text { Qualitative research appraisal } \\
\text { Qualitative research data analysis } \\
\text { Statistics }\end{array}$ \\
\hline & $\begin{array}{l}\text { Module 6: Essentials of clinical training in } \\
\text { obstetric and neonatal care in a low-resource } \\
\text { setting } \\
\text { Introduction to clinical education } \\
\text { Clinical teacher briefing } \\
\text { Learning styles and strategies }\end{array}$ & $\begin{array}{l}\text { How to teach practical skills } \\
\text { Teaching practical skills } \\
\text { On-the-job teaching } \\
\text { Small group mentoring } \\
\text { Interprofessional education }\end{array}$ \\
\hline & \multicolumn{2}{|c|}{$3^{\text {rd }}$ interviews: $\mathrm{N}=39$ trainees, $\mathrm{N}=2$ Registrars } \\
\hline
\end{tabular}

Figure 1 An overview of the enhancing human resources and the use of appropriate technologies for maternal and perinatal survival in sub-Saharan Africa (ETATMBA) training modules when they were delivered and the time points at which interviews were carried out.

All interviews were audio recorded and transcribed verbatim. A study specific Nvivo (V.10) project stored the transcripts and facilitated analysis. WC and DRE coded data with FG providing independent quality checks on $20 \%$ of transcripts early in the coding process. We adopted a thematic approach for analysis. We based coding on the interview schedule and initial reading of the transcripts. We added additional codes as themes emerged from the data. The coding team discussed and agreed on themes and their definitions. We discussed coding discrepancies, and coding definitions were refined. For analysis we used a modification of the process evaluation framework proposed by Steckler and
Linnan. $^{22}$ We present our study process evaluation framework in table 1 .

We extracted data relating to context from the $\mathrm{MOH}$ documents and present selected summary statistics to provide an illustration of the district. The officers from the $\mathrm{MOH}$, who carried out the recruitment of the trainees, provided the overall numbers of NPCs from which they selected; a summary is provided.

\section{RESULTS}

We present the results mapped against our process evaluation categories. Where we provide brief illustrative 
Table 1 Data sources and analyses approaches mapped against our adapted process evaluation framework

\begin{tabular}{|c|c|c|c|}
\hline Framework & Description of framework item & Data source & Analysis approach \\
\hline Context & $\begin{array}{l}\text { Description of geographical } \\
\text { location and summary of perinatal } \\
\text { and maternal mortality in the } \\
\text { intervention districts }\end{array}$ & Malawi Ministry of Health data & Descriptive summary \\
\hline Reach & $\begin{array}{l}\text { Description of the trainees and the } \\
\text { pool of NPCs from which they } \\
\text { were recruited }\end{array}$ & Malawi Ministry of Health data & $\begin{array}{l}\text { The distribution of trainees } \\
\text { across the districts }\end{array}$ \\
\hline Dose delivered & $\begin{array}{l}\text { Delivery of training sessions and } \\
\text { training support }\end{array}$ & $\begin{array}{l}\text { Course documentation } \\
\text { Interviews with obstetricians who } \\
\text { provided support }\end{array}$ & $\begin{array}{l}\text { Interrogation of data for } \\
\text { variation from intended delivery } \\
\text { of training, for example, } \\
\text { non-attendance }\end{array}$ \\
\hline Dose received & $\begin{array}{l}\text { Participation in training by NPCs } \\
\text { and their perceptions of what they } \\
\text { learn }\end{array}$ & $\begin{array}{l}\text { Course attendance registers } \\
\text { First set of interviews with } \\
\text { opportunistic sample of } 19 \text { NPCs }\end{array}$ & $\begin{array}{l}\text { Attendance counts } \\
\text { Thematic analysis of NPC } \\
\text { responses to question 'what } \\
\text { did you learn that was new to } \\
\text { you?' }\end{array}$ \\
\hline \multirow[t]{3}{*}{$\begin{array}{l}\text { Early } \\
\text { implementation }\end{array}$} & $\begin{array}{l}\text { Implementation of initial learning in } \\
\text { the NCP's own clinical working } \\
\text { context particularly leadership } \\
\text { skills }\end{array}$ & $\begin{array}{l}\text { Interviews undertaken with an } \\
\text { opportunistic sample of } 12 \text { NPCs } \\
\text { from the seven intervention districts } \\
6 \text { months after module } 2\end{array}$ & $\begin{array}{l}\text { Interrogation of interviews for } \\
\text { spontaneously given examples } \\
\text { of change in their working style }\end{array}$ \\
\hline & $\begin{array}{l}\text { Evidence of cascading of learning } \\
\text { by NPCs }\end{array}$ & $\begin{array}{l}\text { Interviews with an opportunistic } \\
\text { sample of } 10 \text { cascadees }\end{array}$ & $\begin{array}{l}\text { Thematic analysis of what was } \\
\text { taught by the NPCs to } \\
\text { cascadees }\end{array}$ \\
\hline & $\begin{array}{l}\text { Evidence of cascading of learning } \\
\text { from the perspective of DMOs }\end{array}$ & $\begin{array}{l}\text { Interviews with an opportunistic } \\
\text { sample of five DMOs }\end{array}$ & $\begin{array}{l}\text { Interrogation of interviews for } \\
\text { examples of cascading of } \\
\text { training }\end{array}$ \\
\hline $\begin{array}{l}\text { Later } \\
\text { implementation }\end{array}$ & $\begin{array}{l}\text { Implementation of training up to } \\
\text { attending modules } 5 \text { and } 6\end{array}$ & $\begin{array}{l}\text { Interviews with } 39 \text { NPCs when } \\
\text { attending modules } 5 \text { and } 6\end{array}$ & $\begin{array}{l}\text { Thematic analysis of actual } \\
\text { use of skills used by NPCs }\end{array}$ \\
\hline
\end{tabular}

The opportunistic samples are based on the presence and availability (eg, not interfering with normal workload) of individuals at the time of the researcher's (WC) visit to the facilities.

DMO, District Medical Officers; NPC, non-physician clinician.

quotations from interviews, we identify the role and ID number of the interviewee, and where interviewees were interviewed more than once, we indicate whether it was interview 1, 2 or 3 (see online supplementary appendix for longer versions of quotations).

\section{Context}

The NPCs receiving the intervention worked in hospitals in the following eight districts of Malawi: Lilongwe south, Nkhotakota, Ntcheu, Chitipa, Karonga, Mzimba/ Msusu, Kasungu and Rumphi. For the randomised controlled trial, the control districts were Lilongwe north, Dedza, Dowa, Mchinji, Ntchisi, Salima and Nkhata Bay. All districts have a district hospital; two also have a large central hospital (Lilongwe and Mzimba) and most have rural hospitals. Table 2, adapted from a 2011 Malawi $\mathrm{MOH}$ report, ${ }^{21}$ provides a summary of the population, maternal deaths, stillbirths and neonatal deaths for each of the study districts. The districts are a mix of urban and rural with populations ranging from 172000 to 1905000 (median 397000 ). There is variance across the districts in terms of the number of deliveries each year, with institutional deliveries ranging from 5298 to 53426 (median 12965). Maternal deaths range from
3 to 48 (median 14), stillbirths range from 116 to 988 (median 233) and early neonatal deaths (within $24 \mathrm{~h}$ of birth) range from 4 to 293 (median 100) with the perinatal mortality rate (per 1000 deliveries) ranging from 9.77 to 59.06 (median 24.7; see table 2). ${ }^{21}$

\section{Reach}

Fifty-four trainees were recruited representing $67 \%$ (54/81) of the NPCs working in EmONC in the intervention districts. Of those recruited, $46(85 \%)$ remained in the training programme at the time of the third interview, 25 from the central region of Malawi drawn from nine hospitals (district and central hospitals) and 21 from the northern region drawn from six hospitals (district and central hospitals). One of the smaller districts in the northern region had one ETATMBA trainee working in its district hospital. Nearly all the trainees are men with only two women. Our sample frame of EmONC NPCs included 81 NCPs of whom four were women.

\section{Dose delivered}

Six modules (five taught and one professional project) had been delivered by the time we completed data 
Table 2 An overview of the ETATMBA intervention districts showing population, maternal deaths, stillbirths and neonatal deaths 2010

\begin{tabular}{|c|c|c|c|c|c|c|c|}
\hline & $\begin{array}{l}\text { District } \\
\text { population } \\
(1000)\end{array}$ & $\begin{array}{l}\text { Number of } \\
\text { institutional* } \\
\text { deliveries }\end{array}$ & $\begin{array}{l}\text { Maternal } \\
\text { deaths (all } \\
\text { facilities) } \\
\text { direct† }\end{array}$ & $\begin{array}{l}\text { Maternal } \\
\text { death rate } \\
\text { (per } 1000 \\
\text { deliveries) }\end{array}$ & $\begin{array}{l}\text { Stillbirth } \\
\text { all } \\
\text { facilities }\end{array}$ & $\begin{array}{l}\text { Early } \\
\text { neonatal } \\
\text { deaths } ¥\end{array}$ & $\begin{array}{l}\text { Perinatal } \\
\text { mortality rate } \\
\text { (per } 1000 \\
\text { deliveries)§ }\end{array}$ \\
\hline \multicolumn{8}{|c|}{ Northern region districts } \\
\hline Chitipa & 179 & 7177 & 14 & 1.95 & 133 & 43 & 24.62 \\
\hline Karonga & 270 & 7422 & 14 & 1.89 & 257 & 77 & 44.92 \\
\hline Mzimba & 862 & 27697 & 20 & 0.72 & 430 & 140 & 20.56 \\
\hline Nkhata Bay & 216 & 5298 & 14 & 2.64 & 198 & 115 & 59.06 \\
\hline Rumphi & 172 & 8014 & 5 & 0.62 & 116 & 68 & 23.00 \\
\hline \multicolumn{8}{|c|}{ Central region districts } \\
\hline Dedza & 624 & 17751 & 3 & 0.17 & 327 & 113 & 24.77 \\
\hline Dowa & 558 & 14394 & 20 & 1.39 & 287 & 92 & 26.29 \\
\hline Kasungu & 627 & 16824 & 26 & 1.55 & 395 & 99 & 29.34 \\
\hline Mchinji & 456 & 16800 & 34 & 2.02 & 261 & 100 & 21.49 \\
\hline Nkhotakota & 304 & 8444 & 14 & 1.66 & 156 & 102 & 30.55 \\
\hline Ntcheu & 472 & 16065 & 18 & 1.12 & 153 & 4 & 9.77 \\
\hline Ntchisi & 225 & 6934 & 9 & 1.30 & 127 & 24 & 21.87 \\
\hline Salima & 338 & 11536 & 13 & 1.13 & 208 & 107 & 27.29 \\
\hline Lilongwe & 1905 & 53426 & 48 & 0.90 & 988 & 293 & 23.97 \\
\hline
\end{tabular}

Table adapted from Republic of Malawi Ministry of Health report; Malawi 2010 EmONC needs assessment final report. ${ }^{21}$

*Institutional deliveries - deliveries which take place in a health facility (not home births).

†Direct complications and direct causes of maternal death include: antepartum haemorrhage (APH), postpartum haemorrhage, obstructed/ prolonged labour, ectopic pregnancy, severe abortion complications, retained placenta, ruptured uterus, postpartum sepsis, severe pre-eclampsia/eclampsia. Excludes 'other' direct complications or causes of death including non-severe abortion complications weighted for total number of health centres.

†Early neonatal death was defined as a death occurring within $24 \mathrm{~h}$ after delivery.

$\S$ Perinatal mortality rate $=$ (stillbirths $+v$. early neonatal deaths)/(number of deliveries).

ETATMBA, enhancing human resources and the use of appropriate technologies for maternal and perinatal survival in sub-Saharan Africa.

collection for this process evaluation (see figure 1). The two obstetricians from the UK spent 6 months each in Malawi: the first from January 2012 to June 2012 and the second from July 2012 to January 2013. They rotated to all intervention hospitals, where they worked with each trainee reinforcing the training received during modules. They supported the use of operative skills new to the trainees including undertaking transverse as an alternative to midline incision for caesarean sections and the use of B-Lynch sutures for PPH. They also supported the use of all practical skills learnt through the course including the use of partographs, vacuum extraction, neonatal resuscitation and antibiotic prophylaxis in caesarean section.

Interviews with the trainees indicate that the obstetrician visits were valued, with many noting that the encouragement and support they received has helped to improve them as NPCs.

\section{Dose received}

All trainees attended module $1(54 / 54)$. Five trainees withdrew before module 2, so 49/54 attended. An additional three withdrew between modules 2 and 3, so 46/ 54 attended module 3 . There was no more attrition for the remaining modules with all remaining trainees attending, with 46/54 attending modules 5 and 6 and completing the professional project. Reasons for withdrawal included the inability to find time for course work and switching to other courses.

In all interviews with trainees we found them able to recall, unprompted, some components of the training modules. For understanding dose received, we report specifically on data from the first set of interviews with 19 trainees. In later interviews the data on what they learnt did not add further to the analysis of the first set of interviews about dose received. However, as we report in subsequent sections, the later sets of interviews provided insights about implementation. In these interviews trainees described receiving new learning on neonatal resuscitation (11/19 trainees); PPH (6/19), B-Lynch suture $(5 / 19)$ and audit (5/19); management of breech delivery $(2 / 19)$; cascading of their new knowledge to others (2/19); caesarean section (1/19); infection control $(1 / 19)$; management of eclampsia $(1 / 19)$.

\section{Early implementation}

The second set of interviews gives us insight into the early implementation of the new knowledge and skills the trainees had received. Here we focus on how the trainees work with and transmit new learning to others in their work place (see box 1). Of the 12 trainees interviewed, 10 talked about how the leadership training had helped them work better with those around them. District Health Officers reported that the trainees were 
Box 1 Representative examples of the early implementation of new skills and knowledge*

Obstetrician support and example of skills recalled

The number of $\mathrm{C}$-sections was going up...teaching them vacuum extractions we would improve this.... we used the Kiwi (vacuum extraction equipment). [Obstetrician 2]

The attachment that we had of the obstetrician... we actually were able to change from the routine way of doing things to real evidence based...[T23:3]

When we are resuscitating a new born we gave up very easily...I have learnt that time and improved knowledge on how to resuscitate a new born can make a difference to the life of the baby. [T33:1]

Representative examples of early implementation of skills and knowledge

This course has really helped me to change the way I am interacting with my colleagues... We can start with the positives and end with the negatives, so that has really changed me, this is now how I work, both with my colleagues and the DHO. [T46: 2]

DHOs

I have seen a couple of them doing neonatal and maternal deaths audits and sharing those experiences with other health care workers. Also advocating for change in practice, change in attitude. They have taken a leading role to ensure that prenatal care scales up in this district. [DO 2]

Cascadee

I also learnt as a new thing, clearly defined steps of how to do resuscitation of the baby. [CA 10]

I see myself improving in these areas..., like vacuum extraction, the timing itself...the benefits of doing caesarean section when it is supposed to be done. [CA 5]

That equipment, the Kiwi (vacuum extraction equipment), we were just leaving things because we didn't know how to use it. These guys (the trainees) they helped us to use these things. [CA 12]

New techniques like the condom tamponade, it was quite new to me, at school we did not learn anything about condom tamponade. [CA 3]

We didn't know that when somebody is suffering pre-eclampsia they gave her magnesium sulphate...but after the training now we have it in the labor ward...if it is needed we give magnesium sulphate, then we refer the patient... [CA 14]

Take the example of eclamptic case, everybody was afraid to use magnesium sulphate but now everybody is capable of using magnesium sulphate. [CA 6]

In things like PPH (postpartum haemorrhage), I was trying to tell them memory is not good enough. When you want to remember something you put it on the wall so you don't have to memorise... I actually had to get them to write their posters and put it on the wall, so that you just look at it and you just remember. [Obstetrician 1]

I remember they used get a nurse or an external speaker to come and teach them on a particular topic at the CPD (continuing professional development) session. After their training they decided they could use this particular session to cascade the training. [Obstetrician 2]

He goes out orienting people on the use of vacuum extraction... he goes around in the health centres so the clinicians get skills from him. [D0 6]

${ }^{*}$ The quotations here have been edited; fuller versions can be seen in the online supplementary material. taking leading roles in improving healthcare practice and cascadees indicate that trainees were sharing their knowledge and skills with those around them. Most commonly reported, as having been taught, was neonatal resuscitation. Several cascadees reported improved understanding of the use of procedures they had been unfamiliar with and similarly one reported they received instruction on how to use equipment that until then had remained unused (vacuum extraction equipment). Several reported learning new techniques of managing $\mathrm{PPH}$, including the use of the drugs misoprostol and oxytocin and the condom tamponade. The use of magnesium sulfate to manage pre-eclampsia was a learning experience for several cascadees. Cascadees also talked about the trainees sharing knowledge about infection control, including effective hand washing.

In their interviews, the obstetricians mentioned encouraging or experiencing trainees cascading their learning and district officers described seeing evidence of trainees cascading what they had learnt to their colleagues.

\section{Later implementation}

We report from the interviews with 39 trainees in the third set of interviews. These provide evidence of how they used the various skills and knowledge from their training in clinical practice. We report data from the section of the interview where we prompted for data on each of the key aspects of the training. First, we report on the use of practical skills, then the use of audit skills. Finally, we report on the use of leadership skills, particularly when used in conjunction with practical skills learnt on the course. The subsections under each of the three headings are in frequency order with those discussed the most at the top.

\section{Practical skills}

Twenty-eight of the 39 interviewees mentioned the training about caesarean section, 26 mentioned using the transverse incision as a new skill.

Twenty-seven trainees mentioned neonatal resuscitation as a skill they encountered in the training with 25 giving examples of how they had used the skills in practice. Seventeen indicated that they had cascaded the skill to their colleagues in their facilities. This was not a skill new to them but they described how the training's more systematic approach was previously lacking. Several trainees mentioned upgrading their knowledge about resuscitation and on the length of time to continue resuscitating a baby.

Twenty-three trainees talked about skills in the management of a PPH. Out of these, 19 trainees reported using the skills in practice. Six trainees had used aorta compression; five had used the B-Lynch suture; five had used the condom tamponade; and three had used misoprostol. Two people mentioned coordinating efforts for the management of PPH. 
Fourteen trainees mentioned the training had helped them realise the advantages of monitoring labour with the use of partograms.

Thirteen people mentioned vacuum extraction as a skill they encountered in the ETATMBA training. Most of the trainees mentioned that though it was not a new skill, they had lacked expertise to perform it. The training improved their skill and confidence. Three reported cascading the skill to their colleagues. Several trainees said their clinical judgement had improved as to whether to conduct vacuum extraction or not. For example, where a caesarean section would have been normal practice, vacuum extraction is now considered.

Twelve trainees discussed learning about vaginal breech delivery skills but only two were able to cite examples of how they had used the skills. Several trainees indicated they had managed to cascade the skill to others. Trainees indicated that learning the skills for breech delivery helped reduce the number of caesarean sections (see box 2).

\section{Audit}

Of the 39 trainees participating in the third set of interviews, all had undertaken two audits and 35 mentioned audit as an important skill. Table 3 presents examples of audits and their outcome.

Box 2 Representative examples of the implementation of skills and knowledge*

one of our tutors came. They facilitated changing to the transverse type incision at our institution. It has been adopted... [T12:3]

We used to have a lot of neonatal deaths because of poor skill of resuscitation before ETATMBA, because easily giving up...We've actually seen that the babies that we then used to say no, you can dispose, wait for it to die, have survived, actually very healthy babies. [T30:3]

I applied the B-lynch suture, with my colleague another ETATMBA trainee... we applied it and the patient actually, stopped bleeding. The patient actually went home, was discharged from the facility... it gave me courage, and I did it and it actually saved a life. [T45:3]

At this point in time, we are really following the partogram and we are really taking action on each and every deviation from the normal. Not only ETATMBA students but even the nurses. So we are working together now. [T32:3]

... What we call a Kiwi vacuum extraction...So, patients who could have gone for caesarean section with prolonged labour, we are able to assist them with vacuum extraction. [T1:3]

We managed to cascade the training on breech deliveries... Now after the training, at least most of the nurses at the hospital are able to do this. [T35:3]

Breech delivery, to me it was one of the most difficult scenarios encountered...But after going through this course we have learnt how toy...So, now we are able to deliver, the breech deliveries. [T28:2]

${ }^{\star}$ These quotations have been edited; fuller versions can be seen in the online supplementary material.

\section{Leadership}

Trainees talk with pride, excitement and enthusiasm about leadership training; about how it had helped them bring about changes in clinical care. For many it was a revelation that by taking a different approach they achieved so much. Trainees have developed a collaborative approach to working with colleagues, particularly the nurses, which was not there before; they felt empowered to approach management about issues including being strategic in seeking, finding or using resources. The visiting obstetricians comment positively of the impact of the leadership training (box 3).

\section{DISCUSSION}

The results of this process evaluation indicated that the educational intervention for NPCs was received by the NPCs attending the training and that the NPCs used the training to change their own clinical practice and to influence the clinical practice of others working in their health facility. All the NPCs interviewed were able to provide examples of actual cases where the use of their newly acquired clinical skills had made a difference to the outcome for mother or baby. They were particularly enthusiastic about the leadership training. They drew on this training when making changes to clinical practice in their health facility, when seeking to change the dynamic of teamwork towards a more collaborative approach and when redirecting the use of resources. Trial results will reveal if the changes reported result in a change in perinatal and maternal mortality in the districts.

This study has demonstrated a willingness to change clinical practice in obstetrics resulting from the educational intervention for NCPs. For such change a team of people have to assent to the change, including NCPs in obstetrics, NCPs in anaesthetics, midwives, district medical officers, pharmacy and laboratory staff. For example, changing from caesarean section for breech presentation to vaginal breech delivery requires a culture change for all hospital labour ward personnel, but it has the potential to save maternal deaths from complications of caesarean section and to save scarce healthcare resources that can be used to save the life of another patient. Some NCPs did not report implementing skills learnt that other NCPs had implemented within the timeframe of our evaluation. The educational intervention was a combination of 1-week lecture courses, emergency simulations, one-to-one clinical on-the-job training and leadership training. This was considerably more substantial than other existing, emergency obstetric, 3-day courses. ${ }^{23}$ We suggest that this multifaceted educational approach to change clinical practice is a powerful and novel way of reducing the burden of maternal and neonatal mortality in sub-Saharan Africa.

A number of published studies have examined the engagement of NPCs in surgical work. Three papers 
Table 3 Examples of audits and the outcome of the audit reported by ETATMBA trainees at interview

\begin{tabular}{|c|c|}
\hline Audit topic* & Example of audit outcome reported at interview \\
\hline Use of partographs & $\begin{array}{l}\text { Trainee found that nurses/midwives were not completing the partograph routinely. After presenting } \\
\text { audit findings at team meeting and providing training there was change in practice: } \\
\text { So, what we see today is, any patient going to labour ward the nurse fill out the labour graph, and } \\
\text { record and monitor. They now see that the monitoring aspect has a bearing on the outcome [9:3] }\end{array}$ \\
\hline $\begin{array}{l}\text { Management of } \\
\text { pre-eclampsia and } \\
\text { eclampsia }\end{array}$ & $\begin{array}{l}\text { I went to the DNO with my findings... most of the health centres don't have magnesium sulphate... } \\
\text { they are afraid to give magnesium sulphate and they cannot order the drug... For this year I have } \\
\text { not seen any death from eclampsia... we are able to manage them there because they are } \\
\text { stabilised (at the health centre) before they arrive (at the hospital) [T40:3] }\end{array}$ \\
\hline Postabortion care & $\begin{array}{l}\text { Trainee noted that current system was chaotic and that there was a lack of instruments } \\
\text { (During the audit) in the pharmacy I found equipment, (lying unused)...I distributed it around the } \\
\text { health centres... I conducted some training like to teach them how to do a vacuum extraction, how } \\
\text { to take care of a vacuum extractor...for the instruments to stay longer. So, it has really given me a } \\
\text { clue, of trying to check some things, doing this now and again as a way of improving services } \\
\text { [T2:3] } \\
\text { Another trainee's audit revealed patients were being sent for evacuations in theatre unnecessarily } \\
\text { and so incurring unnecessary cost when MVAs were more appropriate } \\
\text {...patients who were meant for MVA's were sent for evacuations in theatre. So, looking at the cost } \\
\text { it was, actually the cost was high...just because maybe there wasn't enough equipment for } \\
\text { MVA's, so I discussed that with the management and they bought some sets and we proceeded } \\
\text { doing MVA's [T32:3] }\end{array}$ \\
\hline Neonatal sepsis & $\begin{array}{l}\text { An audit of neonatal services found high sepsis rates in neonates. Reporting findings back to the } \\
\text { group had a positive impact on practice } \\
\text { The sepsis (rate) has reduced by this time after the auditing [T12:3] }\end{array}$ \\
\hline Neonatal resuscitation & $\begin{array}{l}\text { Audit found clinical staff were not following the step-by-step procedure for neonatal resuscitation } \\
\text { and not documenting the procedure. After sharing the results of the audit and training of } \\
\text { colleagues there was improvement in the following of the step-by-step procedure } \\
\text {...previously probably we were not putting things in order and then with the ETATMBA students } \\
\text { they have drilled us to follow each step...we are resuscitating step by step...[NMW cascadee] }\end{array}$ \\
\hline $\begin{array}{l}\text { Postpartum } \\
\text { haemorrhage }\end{array}$ & $\begin{array}{l}\text { An audit revealed colleagues were not checking vital signs when patients were and the hospital } \\
\text { did not have misoprostol for controlling the bleeding. After presenting to the management and } \\
\text { colleagues the management agreed to stock misoprostol and he saw a change in practice in } \\
\text { terms of checking for vital signs } \\
\text { Another audit resulted in change in practice as follows: } \\
\text { Every patient from now, whether from the health centre or not, if they can't get access for two IV } \\
\text { (intravenous) lines they are able now to put even one at least, which is ok. Instead of leaving the } \\
\text { patient alone with the driver (of car bringing the patient to hospital), at least they are able from the } \\
\text { health centres to send somebody to accompany the patient in case of any problems [T9:3] }\end{array}$ \\
\hline
\end{tabular}

${ }^{*}$ Audit topics in descending order of frequency reported.

ETATMBA, enhancing human resources and the use of appropriate technologies for maternal and perinatal survival in sub-Saharan Africa; MVA, manual vacuum aspirations.

report evaluation of additional training given to NPCs. All report that training NPCs in specific skills (not obstetrics or neonatal care) is feasible and that NCPs can safely perform surgical procedures with the right training and support. ${ }^{1424} 25$ None of these papers evaluates how the training is implemented into clinical practice. A study in 2010 reports interviews with NPCs undertaking gynaecological procedures in Malawi. The study found NCPs felt at ease performing operations but the study highlighted the need for training and support. ${ }^{13}$ A recently reported trial of an intervention in Malawi covering the years prior to our study demonstrated an improvement in maternal and neonatal mortality rates. $^{26} 27$ This intervention included quality improvement intervention at health facilities along with a participatory women's group community intervention.
A limitation of our intervention is that it is limited to training NCPs who may not remain working in the same health facility.

Process evaluations are increasingly important in the evaluation of health interventions to place the effectiveness/non-effectiveness of the intervention in context. ${ }^{19}$ The conduct of process evaluations is being established in Africa in maternal and child health research and evaluations of HIV/AIDs programmes. ${ }^{27-31}$ Our process evaluation suggests there has been real change in the skills of these NPCs and an enhancement of the professionalism of this group. However, changes in clinical practice may not yet be sufficiently consistent to impact on perinatal and maternal mortality. The huge variations in mortality rates across districts at baseline may prove to be a confounding factor in translating our very positive 
Box 3 Representative examples of the trainees using their leadership skills to improve practice in their facilities

We share...We work as a team. [T41:3]

Nurses were going through the training for newborn resuscitation...I was able to organise a good area for resuscitation and lobby for more resource from the DHO. [T15:3]

Some said no, they are not working because maybe they were worn out things (equipment)... We looked around and we found things here and there and actually we have now replaced them. [T14:3]

We complain that we don't have blood in the laboratory...After this training, if a patient donates blood for a procedure, if we see that this patient do not require this blood, we keep it and channel it to a patient that may be in dire need of blood. [T23:3]

I wanted the relationship between them and other clinicians to improve so they would work as a team not as individuals... The midwives would come to say "we never used to do these things with NPC's before, but you know they don't now wait to be called they come and check with us what is going on and we would tell them and we would discuss management". [Obstetrician]

(I saw them) taking on some leadership roles because they were respected. They were actually doing their audits and some had results with them so they presented to the district health management team...(about) things that they wanted to change. [Obstetrician 2]

${ }^{*}$ These quotations have been edited; fuller versions can be seen in the online supplementary material.

qualitative findings into sustainable reductions in mortality rates but highlight the need to improve the quality of care with the cadre of health workers available.

A limiting factor in this study may have been that trainees are likely to report what they consider to be socially acceptable to the evaluation team. However, they were reporting actual examples where lives had been saved, such as preventing the death of a woman from PPH, and provided detail that suggested these events had actually happened. However, the trainees are likely to remember and report these dramatic events, but these events may be rare. Our assessment of the cascading of training was limited as we only interviewed cascadees who had received training. These limitations caution us that the results of the clinical trial may not be as positive as the interview accounts suggest.

During the delivery of the intervention, over time, there was concurrent delivery within the districts involved in this trial (intervention and control districts) of other training initiatives from non-government organisations for all relevant health professionals on neonatal resuscitation. This is likely to improve perinatal outcome in intervention and control districts and is a confounding variable to the trial results.

Task shifting in countries like Malawi is at present necessary for the provision of healthcare. NPCs provide and are likely to continue to provide the majority of healthcare for low resource countries in much of sub-Saharan Africa. Here we have evaluated a model of training for these clinicians with an emphasis on problem solving through leadership, audit and service improvement. During the process of developing and establishing the training it became clear that raising the status and quality of the educational experience through accreditation was a vital strategy. In Malawi, this approach has now been extended to train a further 60 NPCs in obstetrics and five other specialties, supported by the Malawi $\mathrm{MOH}$, College of Medicine and faithbased organisations. While much remains to be done, shared leadership training that empowers NCPs to produce clinical service improvement has potential to improve the health of mothers and babies in Africa.

\section{Author affiliations}

${ }^{1}$ Warwick Clinical Trials Unit, Division of Health Sciences, Warwick Medical

School, The University of Warwick, Coventry, UK

${ }^{2}$ College of Medicine, Malawi University, Blantyre, Malawi

${ }^{3}$ Educational Development \& Research Team, Warwick Medical School,

The University of Warwick, Coventry, UK

${ }^{4}$ Division of Metabolic \& Vascular Health, Warwick Medical School,

The University of Warwick, Coventry, UK

${ }^{5}$ Obstetrics and Gynaecology Department, Malawi University, College of Medicine, Blantyre, Malawi

${ }^{6}$ Division of Reproductive Health, Warwick Medical School, The University of Warwick, Coventry, UK

${ }^{7}$ Division of Health Sciences, Warwick Medical School, The University of Warwick, Coventry, UK

Collaborators Authors acting on behalf of the ETATMBA study group below. The ETATMBA Study Group-FK, Chisale Mhango, WC, Chikayiko Chiwandira and Queen Dube, University of Malawi College of Medicine, Malawi; Fannie Kachale and Chimwemwe Mvula, Ministry of Health, Malawi, Malawi; Godfrey Mbaruku, Paul Kihaile, Sidney Ndeki, Hamed Mohamed, Senga Pemba, Aloisia Shemdoe and Festo Mazuguni, Ifakara Health Institute, Tanzania; Staffan Bergström, Karolinska Institutet, Sweden; Alan Davies, GE Healthcare, UK; JPO'H, SQ, Douglas Simkiss, DD, DRE, FG, Ngianga-bakwin, Kandala, Anne-Marie Brennan, Edward Peile, Anne-Marie Slowther, Saliya Chipwete, Paul Beeby, Gregory Eloundou, Harry Gee and Vinod Patel, The University of Warwick, UK

Contributors DRE, JPO, WC, FK, SQ and FG were involved in conception and design of the study. DRE drafted the manuscript supported by all authors. JPO, FK, SQ, and DD are responsible for the design, management and delivery of the training.

Funding This work was funded by the European Commission, Seventh Framework Programme. Project no. 266290.

Competing interests JPO (FRCP, MD) is the principal investigator for the trial and is Director of Quality Assurance at Warwick Medical School (UK). DRE $(\mathrm{PhD})$ is a Senior Research Fellow in the Warwick Clinical Trials unit (UK) and has expertise in research design, implementation and evaluation. FG (PhD) is Professor of Medicine in Society, Division of Health Science, Warwick Medical Schools, The University of Warwick (UK). FK (MD, PhD) is a Consultant Obstetrician/Gynaecologist and is principal investigator for the trial at College of Medicine, Malawi. SQ (MD, MRCOG) is Professor of Obstetrics Honorary Consultant Obstetrician at University Hospitals Coventry and Warwickshire (UK) with research interests being translational research into recurrent miscarriage, implantation, preterm and dysfunctional labour, and obesity in pregnancy. $\mathrm{DD}(\mathrm{PhD})$ is an Associate Professor (Reader) in the Warwick Medical School Educational Development \& Research Team. His research interests are primarily in global health education and educational technology and e-learning in medical education. WC is a researcher and PhD student at the College of Medicine, Malawi.

Ethics approval The study was approved by the Biomedical Research Ethics Committee (BREC) at the University of Warwick, UK (143/09/2011) and The College of Medicine research ethics committee (COMREC), Malawi (P.07/11/ 1102). It has the approval and support of the Ministry of Health, Malawi. 
Provenance and peer review Not commissioned; externally peer reviewed.

Data sharing statement No additional data are available.

Open Access This is an Open Access article distributed in accordance with the Creative Commons Attribution Non Commercial (CC BY-NC 4.0) license, which permits others to distribute, remix, adapt, build upon this work noncommercially, and license their derivative works on different terms, provided the original work is properly cited and the use is non-commercial. See: http:// creativecommons.org/licenses/by-nc/4.0/

\section{REFERENCES}

1. WHO. The World Health Report: working together for health. Geneva: World Health Organisation, 2006.

2. Anyangwe SC, Mtonga C. Inequities in the global health workforce: the greatest impediment to health in sub-Saharan Africa. Int $J$ Environ Res Public Health 2007;4:93-100.

3. UNICEF. State of the world's children. New York: United Nations Children and Education Fund, 2009.

4. Ronsmans C, Graham WJ. Maternal mortality: who, when, where, and why. Lancet 2006;368:1189-200.

5. Lawn JE, Kinney M, Lee AC, et al. Reducing intrapartum-related deaths and disability: can the health system deliver? Int J Gynaecol Obstet 2009;107(Suppl 1):S123-40, S40-2.

6. Bergstrom $\mathrm{S}$. Who will do the caesareans when there is no doctor? Finding creative solutions to the human resource crisis. BJOG 2005;112:1168-9.

7. Chilopora G, Pereira C, Kamwendo F, et al. Postoperative outcome of caesarean sections and other major emergency obstetric surgery by clinical officers and medical officers in Malawi. Hum Resour Health 2007;5:17.

8. McCord C, Mbaruku G, Pereira C, et al. The quality of emergency obstetrical surgery by assistant medical officers in Tanzanian district hospitals. Health Aff (Millwood) 2009;28:w876-85.

9. Mullan F, Frehywot S. Non-physician clinicians in 47 sub-Saharan African countries. Lancet 2007;370:2158-63.

10. Pereira C, Bugalho A, Bergstrom S, et al. A comparative study of caesarean deliveries by assistant medical officers and obstetricians in Mozambique. Br J Obstet Gynaecol 1996;103:508-12.

11. Pereira C, Cumbi A, Malalane R, et al. Meeting the need for emergency obstetric care in Mozambique: work performance and histories of medical doctors and assistant medical officers trained for surgery. BJOG 2007;114:1530-3.

12. Wilson $A$, Lissauer $D$, Thangaratinam $\mathrm{S}$, et al. A comparison of clinical officers with medical doctors on outcomes of caesarean section in the developing world: meta-analysis of controlled studies. BMJ 2011;342:d2600.

13. van Amelsfoort JJC, van Leeuwen PAM, Jiskoot $P$, et al. Surgery in Malawi-the training of clinical officers. Trop Doct 2010;40:74-6.

14. Wilhelm TJ, Thawe IK, Mwatibu B, et al. Efficacy of major general surgery performed by non-physician clinicians at a central hospital in Malawi. Trop Doct 2011;41:71-5.

15. Bradley S, McAuliffe E. Mid-level providers in emergency obstetric and newborn health care: factors affecting their performance and retention within the Malawian health system. Hum Resour Health 2009;7:14.
16. McAuliffe $\mathrm{E}$, Bowie $\mathrm{C}$, Manafa $\mathrm{O}$, et al. Measuring and managing the work environment of the mid-level provider-the neglected human resource. Hum Resour Health 2009;7:13.

17. WHO. WHO recommendations: optimizing health worker roles to improve access to key maternal and newborn health interventions through task shifting. Geneva: World Health Organisation, 2012.

18. Ellard D, Simkiss D, Quenby S, et al. The impact of training non-physician clinicians in Malawi on maternal and perinatal mortality: a cluster randomised controlled evaluation of the enhancing training and appropriate technologies for mothers and babies in Africa (ETATMBA) project. BMC Pregnancy Childbirth 2012;12:116.

19. Ellard D, Parsons S. Process evaluation: understanding how and why interventions work. In: Thorogood M, Coombes $\mathrm{Y}$, eds. Evaluating health promotion practice and methods. 3rd edn. Oxford: Oxford University Press, 2010:87-104.

20. Brennan A-M. ETATMBA: Enhancing human resources and the use of appropriate technologies for maternal and perinatal survival in sub-Saharan Africa. Secondary ETATMBA: Enhancing human resources and the use of appropriate technologies for maternal and perinatal survival in sub-Saharan Africa. [Web Pages] 20 Nov. 2013. http://www2.warwick.ac.uk/fac/med/about/global/etatmba/about/

21. Ministry of Health. Malawi 2010 EmONC needs assessment final report. Republic of Malawi Ministry of Health, 2011.

22. Steckler A, Linnan L, eds. Process evaluation for public health interventions and research. San Francisco: Jossey-Bass, 2002

23. Grady K, Ameh C, Adegoke A, et al. Improving essential obstetric and newborn care in resource-poor countries. J Obstet Gynaecol 2011;31:18-23.

24. Labhardt ND, Balo JR, Ndam M, et al. Task shifting to non-physician clinicians for integrated management of hypertension and diabetes in rural Cameroon: a programme assessment at two years. BMC Health Serv Res 2010;10:339.

25. Wilhelm TJ, Mothes H, Chiwewe D, et al. Gastrointestinal endoscopy in a low budget context: delegating EGD to non-physician clinicians in Malawi can be feasible and safe. Endoscopy 2012;44:174-6.

26. Colbourn T, Nambiar B, Bondo A, et al. Effects of quality improvement in health facilities and community mobilization through women's groups on maternal, neonatal and perinatal mortality in three districts of Malawi: MaiKhanda, a cluster randomized controlled effectiveness trial. Int Health 2013;5:180-95.

27. Colbourn T, Nambiar B, Costello A, et al. Final evaluation report. The impact of quality improvement at health facilities and community mobilisation by women's groups on birth outcomes: an effectiveness study in three districts of Malawi. 2013. http://www.health.org.uk/ publications/maikhanda/ (accessed 09/07/2014).

28. Georgeu D, Colvin CJ, Lewin S, et al. Implementing nurse-initiated and managed antiretroviral treatment (NIMART) in South Africa: a qualitative process evaluation of the STRETCH trial. Implement Sci 2012;7:66.

29. Hargreaves J, Hatcher A, Strange V, et al. Process evaluation of the Intervention with Microfinance for AIDS and Gender Equity (IMAGE) in rural South Africa. Health Educ Res 2010;25:27-40.

30. Ridde V, Diarra A. A process evaluation of user fees abolition for pregnant women and children under five years in two districts in Niger (West Africa). BMC Health Serv Res 2009;9:89.

31. Ronsmans C, Etard JF, Walraven G, et al. Maternal mortality and access to obstetric services in West Africa. Trop Med Int Health 2003;8:940-8 